\title{
El impacto del uso de la imagen en la cuenta de Twitter de CSIC
}

\section{The impact of using images on CSIC's Twitter profile}

\section{0 impacto do uso da imagem no perfil do CSIC no Twitter}

\author{
Aitor González Bengoechea \\ Investigador predoctoral en formación \\ Doctorando en Comunicación Audiovisual, Publicidad y Relaciones Públicas \\ (Universidad Complutense de Madrid) \\ http://orcid.org/0000-0002-1509-8106 \\ España
}

Fecha de recepción: 13 de noviembre de 2019

Fecha de revisión: 18 de abril de 2019

Fecha de aceptación: 5 de diciembre de 2019

Fecha de publicación: 1 de enero de 2020

Para citar este artículo: González Bengoechea, A. (2020). El impacto del uso de la imagen

en la cuenta de Twitter de CSIC, Icono 14, 18 (1), 205-230. doi: 10.7195/ri14.v18i1.1273 


\section{Resumen}

La ciencia es uno de los campos de conocimiento más importantes de los que dispone el ser humano y tiene en la comunicación una de las principales bazas para divulgar sus descubrimientos, novedades, actualidad y sucesos destacables. Una comunicación científica que tiene en la imagen un soporte mediante el que mostrar conceptos de forma visual que a veces pueden ser dificilmente explicables únicamente mediante la palabra. Internet primero y las redes sociales después han cambiado los esquemas de la comunicación tal y como se conocían hasta su aparición. Facebook, Twitter o Instagram cuentan por cientos de millones sus usuarios, lo que ha sido valorado por las instituciones y organizaciones, incluidas las científicas. Estas redes sociales, en especial Twitter, se han erigido como un nuevo canal de comunicación más accesible que los medios tradicionales, con un mayor número de potenciales receptores, sobre todo para organizaciones sin los recursos necesarios para obtener presencia en dichos medios. El presente trabajo analiza el perfil en Twitter del Consejo Superior de Investigaciones Científicas (CSIC) para conocer la utilización que el organismo hace de las imágenes en los mensajes que envia en la red social. Según los resultados el CSIC hace un uso mayoritario de la imagen, sobre todo de ilustraciones o fotografias que muestran lo que se presenta en el texto del mensaje. Gracias a esta utilización de las imágenes, el CSIC aumenta sus impactos en la red social, con un mayor número de interacciones por parte de los usuarios.

Palabras clave: Imagen; Ciencia; Redes Sociales; Difusión; Twitter; CSIC

\section{Abstract}

Science is one of the most important fields of knowledge to people and communication has one of the main strengths to disseminate their discoveries, news, current events and outstanding events. This scientific communication has in the image a support through which to show concepts in a visual way that can sometimes be difficult to explain only by words.

Internet first and social media then have changed the communication schemes as they were known until they appeared. Facebook, Twitter or Instagram have hundreds of millions of users, which has been valued by institutions and organizations, including scientific ones. These social media, especially Twitter, have emerged as a 
new communication channel more accessible than traditional media, with a greater number of potential recipients, especially for organizations without the resources to obtain a presence in those traditional media.

This work analyzes the Twitter profile of the Consejo Superior de Investigaciones Cientificas (CSIC) to see how the institution uses images in the messages that sends on Twitter. According to the results, the CSIC makes a majority use of the image, especially of illustrations or photographs that show what is presented in the text of the message. Thanks to this use of images, CSIC increases its impact on the social network, with a greater number of interactions by users.

Key Words: Image; Science; Social Media; Diffusion; Twitter; CSIC

\section{Resumo}

A ciência é um dos campos de conhecimento mais importantes que o ser humano possui, tendo na comunicação um dos principais ativos para disseminar suas descobertas, notícias, assuntos atuais e eventos relevantes. Uma comunicação científica que tem suporte na imagem e através da qual é possivel exibir conceitos visualmente que às vezes podem ser dificeis de explicar apenas através da palavra.

A Internet primeiro e as redes sociais depois mudaram os esquemas de comunicação, tal como eram conhecidos. 0 Facebook, Twitter ou Instagram representam centenas de milhões de usuários, valorizados por instituições e organizações, inclusive científicas. Essas redes sociais, especialmente o Twitter, surgiram como um novo canal de comunicação mais acessível que os mídia tradicionais, potencialmente com um maior número de destinatários, principalmente para as organizações sem os recursos necessários para obter presença nessas mídias.

Este artigo analisa o perfil do Twitter do Consejo Superior de Investigaciones Científicas (CSIC) relativamente ao uso de imagens no corpo das mensagens enviadas nesta rede social. De acordo com os resultados, o CSIC faz uso maioritário da imagem, especialmente de ilustrações ou fotografias que revelam o que é apresentado no texto da mensagem. Graças a esse uso de imagens, o CSIC aumenta o seu impactos na rede social, com um número mais elevado de interações dos usuários.

Palavras chave: Imagem; Ciência; Redes Sociais; Divulgação; Twitter; CSIC 


\section{Introducción}

Una fotografía en blanco y negro, una página publicitaria en un periódico, una postal turística, un dibujo esquemático, una imagen de un microscopio, una pintura hecha con barro al abrigo de una ladera... Toda imagen conlleva un conjunto de notaciones y connotaciones que el receptor procesa dotándola de significado y sentido. Es decir, toda imagen comunica.

Y comunica mediante los distintos medios, soportes, géneros y formatos a través de su naturaleza icónica, ya sea visual, sonora o audiovisual. Camusso y Marchetti (2002) entienden la imagen así:

Dispositivo conceptual y formal que pone en relación a diferentes actores a partir de la articulación estratégica de códigos visuales, lingüísticos, recursos estéticos, modos de representación, inscriptos en la complejidad de un momento socio histórico particular que define los límites y los alcances de ese contrato. (p.102)

La comunicación por la imagen es más que un intercambio de mensajes, es una construcción interactiva de sentido que se produce cuando "la comunicación entra en sinergia con los ámbitos cognitivos y emotivos" (Goyes, 2003, p.46). Esto supone que sus mensajes variarán o influirán en el receptor en función de sus características propias, como su nivel de cultura, su estatus socioeconómico o su contexto de recepción ya que “la imagen 'leída' es portadora de sentido pues ofrece resonancias con la propia narración interna para conectar con todas las posibilidades de interpretación (personal, contextual, social, cultural y simbólica)" (Abad, 2012, p.2). Frascara (2015) también opina que toda imagen, ilustración, fotografía, etc. situada ante la mirada de un receptor comunica "un espectro impredecible de mensajes" (p.13), pues "el poder de las imágenes está basado en la reacción total que una persona experimenta en toda comunicación" (p.63).

Cada vez estamos más expuestos a la influencia que la imagen tiene, no solo en la comunicación, sino en nuestra forma de pensar y actuar. La fotografía, junto con el cine, la televisión e internet, han ganado una presencia protagonista en las sociedades modernas construyendo la Sociedad de la Imagen, donde se consolidan 
fuentes y medios de reproducción de imágenes y donde la imagen se sitúa como un soporte masivo de comunicación icónica (Pantoja, 2007, p.188). Las imágenes son una alternativa más para comunicar un mensaje, para difundir el conocimiento o para informar de unos hechos y son utilizadas tanto por las personas, como por los responsables de la enseñanza y las asociaciones, empresas o instituciones que comunican sus aspectos e informaciones, también en el ámbito científico.

La ciencia es uno de los ámbitos que recurre a la imagen para comunicar un contenido o clarificarlo, destinado a la formación de nuevos científicos, la divulgación o la difusión de sus investigaciones y descubrimientos. Es a finales del s. XX cuando se supera el rechazo a la imagen como recurso argumentativo y se empiezan a aprovechar las potencialidades de las, cada vez más, innovaciones tecnológicas que favorecían y facilitaban la utilización de recursos gráficos (Otero, Moreira \& Greca, 2002, p.130).

La utilización de la imagen con finalidades comunicativas vivió con el desarrollo tecnológico un nuevo impulso a finales del siglo pasado. A principios de los años 90, Tim Berners Lee crea la World Wide Web y desde entonces internet no ha parado de crecer en número de usuarios y en alcance mundial hasta convertirse en un elemento más de la sociedad, llegando a protagonizar la denominada Tercera Revolución Industrial. Más tarde, a principios del s. XXI, fruto de ese constante desarrollo aparece la denominada Web 2.0, un nuevo internet en el que la interacción y la participación se vieron potenciados, haciendo que el usuario dejara de ser un único receptor para convertirse también en un creador de contenidos, dando pie a la aparición de las redes sociales (0'Reily, 2006; Celaya, 2011, p.30; Martínez de Salinas, 2015, p.61).

La llegada de internet, que ha facilitado la distribución de imágenes, así como el auge de los dispositivos móviles que agilizan su envío entre personas ha promovido que las imágenes se conviertan en "el idioma preferido en las prácticas de comunicación mediadas" (Van Dijck, 2008, p.58). Todo ello, sumado al potencial interactivo y visual con el que cuentan las redes sociales, ha revitalizado la utilización de la imagen en la comunicación y transmisión de conocimiento científico (0tero, Moreira \& Greca, 2002, p.130). Explica Perales (2006) que “las nuevas tecnologías proporcionan una oportunidad potencialmente fructífera como fuente de recursos 
audiovisuales" (p.23), y puntualiza que, en el caso del conocimiento científico, el uso de las imágenes "debe estar marcado por actividades específicas, tales como la clarificación de los propios signos gráficos, la adecuada correlación con el texto escrito, la simultaneidad de las observaciones de los planos real y simbólico" (p.23).

Las redes sociales se han convertido en un elemento más de la sociedad y permiten construir un perfil público, elaborar una lista de usuarios con los que compartir conexión y establecer relaciones personales, profesionales o intercambiar informaciones (Berlanga \& García, 2014, p.101). Las redes sociales hacen posible un discurrir casi gratuito de la información y el conocimiento y alteran el modo en el que los ciudadanos se relacionan con las empresas, las instituciones y la Administración (Díaz, 2015, pp.8-9).

El auge de la interactividad que proporcionan la Web 2.0 y las redes sociales ha generado también un nuevo tipo de receptor-usuario, el nativo digital, que se opone al inmigrante digital (Prensky, 2001). Esta diferencia no es generacional, sino que supone una brecha cognitiva en creciente ascenso, teniendo los nativos digitales el primer contacto con la cultura a través de la tecnología y no del papel, por primera vez en la historia (Piscitelli, 2006, p.182).

Los nativos digitales procesan la información muy rápidamente y funcionan mejor cuando están en red, utilizándola para socializar, aprender y conversar, llegando a no comprender una realidad sin internet ni las redes sociales (Prensky, 2001, p.2; Noguera, Martínez \& Grandío, 2011, p.49; García, 2014, p.249). Estos nativos cuentan también con la responsabilidad de convertirse en un "agente enculturalizador de las generaciones anteriores" (García \& Gértrudix, 2009, p.23), como la de los inmigrantes digitales, personas que "proceden de otros entornos tecnológicos y usos de comunicación" (p.26). Los inmigrantes digitales han tenido que adaptarse al nuevo entorno arrastrados por las necesidades laborales y profesionales y cuentan con hábitos de su pasado analógico, como leer las instrucciones en papel o no recurrir a internet como primera fuente de información, menospreciando además los hábitos de los nativos digitales por ser diferentes (García, 2014, p.246; Prensky, 2001, p.2).

Del mismo modo en que la sociedad y los usuarios han cambiado fruto del auge de internet y de las redes sociales, las empresas, organizaciones e instituciones 
han tenido también que adaptar su comunicación para llegar a los nuevos usuarios de una forma efectiva y beneficiosa. Al respecto, Noguera, Martínez y Grandío (2011, p.11) defienden que internet y las redes sociales han provocado un cambio en la manera en la que la sociedad y las organizaciones se comunican y conversan en esquemas de comunicación mucho más complejos donde intervienen y aparecen actores que no pueden ser controlados. De hecho, el auge de estas tecnologías ha dado pie a la bautizada como Sociedad Red, una estructura social que se basa en las redes digitales que "generan, procesan y distribuyen información" y donde las estructuras sociales y las comunicaciones entre los agentes económicos, políticos y sociales se produce en torno a esas redes digitales (Castells, 2005, p.7).

La comunicación de las organizaciones ya tiene en cuenta a internet y las redes sociales, cuyo valor comunicativo no debe ser ignorado a la hora de planificar estrategias y planes de comunicación (Hernández \& Subiela, 2012, p.80). Con las redes sociales como un nuevo canal de comunicación, las organizaciones han visto, en primer lugar, que ahora pueden realizar una comunicación directa con sus públicos, sin intermediarios, y en segundo lugar, que ahora los mensajes que lanzan son globales y sus impactos inmediatos (López \& Cuesta, 2012, p.24). Además de ello, las redes sociales también permiten a las organizaciones dar a los usuarios "una gran cantidad de información en pequeñas dosis a la vez que crea una comunidad en la que puede integrarse todo aquel que está interesado que recibir información institucional de primera mano" (Fernández, 2015, p.419).

El campo científico no ha permanecido impermeable a estos cambios comunicativos y las redes se han convertido también en fuente de información científica, especialmente para los nativos digitales. Como se recoge en la VII Encuesta sobre la Percepción Social de la Ciencia y la Tecnología que realiza FECYT, “las generaciones más jóvenes acceden a la información científica a partir de un uso más intenso y diverso de recursos y canales online de corte no periodístico", como redes sociales, YouTube o Wikipedia (Revuelta \& Corchero, 2016, p.201). Este estudio presenta que las redes sociales son el primer medio de acceso a la información científica entre los menores de 55 años, siendo la segunda opción para los mayores de dicha edad. Facebook y Twitter son las más utilizadas para el acceso a la información científica. 


\section{ARTÍCULOS DE INVESTIGACIÓN}

Twitter dispone de una ventaja sobre el resto de redes sociales en lo que a comunicación e información se refiere por posibilidades como los retuits o la elaboración de hilos de mensajes, además de su inmediatez, algo presente en todas las redes sociales pero que cobra especial relevancia en el caso de Twitter. Esta red social dota a las organizaciones del control de la información, convirtiéndose en una fuente primaria de información y pudiendo comunicar sus actividades en tiempo real e incluso con usuarios en concreto, lo que les aporta credibilidad y les acerca a sus públicos. En Twitter las organizaciones pueden incluir imágenes, vídeos, etiquetas o retuitear publicaciones, lo que les ayuda a aumentar sus impactos (Fernández, 2015, p.416).

La principal característica de Twitter es la limitación de 280 caracteres en sus mensajes, lo que ha hecho que llegue a ser considerada como un servicio de microblogging en vez de una red social. Su funcionamiento se basa en la emisión de mensajes cortos para los usuarios que siguen al perfil, conocidos como followers, que cuentan con la posibilidad de contestar, retuitear o pulsar "Me Gusta" al mensaje en sí. También aparecen otras funcionalidades como las etiquetas o hashtags, a través de las cuales se pueden filtrar contenidos o aumentar el alcance de los mensajes emitidos, que pueden llegar a convertirse en Trending Topic, los temas más hablados en ese momento en Twitter.

Pese a contar con menos usuarios que otras redes sociales como Facebook o Instagram, Twitter ha sabido buscar su posicionamiento entre los usuarios potenciando su carácter informativo y su instantaneidad y afirmando que su misión es hacer posible que "las personas cuenten lo que está pasando en el mundo en este momento" (Twitter, s.f.a), desde distintos puntos de vista y con un carácter internacional y global. Algo valorado por los usuarios y también por las organizaciones, que acuden a esta red social como otro canal más de comunicación en el que relacionarse con sus públicos. En cuanto a las cifras, desde su nacimiento en 2006 Twitter ha ido creciendo exponencialmente hasta llegar a los 330 millones de usuarios en todo el mundo (Statista, 2018), mientras que en España la cifra se sitúa en los 4,9 millones (Cardeñosa, 2018). 


\section{El CSIC en la red}

Así se llega al organismo que compone el objeto de estudio del presente trabajo, el Consejo Superior de Investigaciones Científicas (CSIC). Esta institución tiene su origen a principios del s. XX, cuando en 1907 se crea la Junta para Ampliación de Estudios e Investigaciones Científicas (JAE) con la que, bajo la presidencia de Santiago Ramón y Cajal, “se pretendía terminar con el aislamiento español y enlazar con la ciencia y la cultura necesarias en las esferas de la ciencia, la cultura y la educación" (CSIC, s.f.A). Esta institución formó a numerosos médicos, biólogos, químicos y hombres y mujeres de ciencia en general hasta la Guerra Civil, cuando cesó su actividad. Tras el conflicto bélico, en noviembre de 1939 la JAE se disolvió y pasó a llamarse como es conocido hoy en día (CSIC, s.f.a).

Tras el periodo franquista, con la vuelta de la democracia, el CSIC recupera sus principales competencias originales como la ejecución de investigaciones o la formación de personal investigador y técnico, promoviendo las relaciones con las universidades, y se le suma la responsabilidad de elaborar la política científica y fomentar relaciones científicas tanto internas como externas. Ya en el s. XXI el organismo se adapta a la nueva realidad, transformándose en agencia mediante un decreto en 2007 con el objetivo de que disponga de mayor agilidad y autonomía, dotando a la presidencia, en manos de Rosa María Menéndez López desde 2017, de carácter ejecutivo y articulando sus actividades en contratos de gestión, basados “en los principios de calidad, transparencia y evaluación” (CSIC, s.f.b).

Actualmente, como recoge la memoria del año 2017, el CSIC cuenta con 120 institutos de investigación tanto propios como mixtos, dentro de los cuales trabajan 11.085 profesionales científicos, investigadores en formación, técnicos y de gestión. Durante el año 2017 se han contabilizado más de 3.000 proyectos de $\mathrm{I}+\mathrm{D}+\mathrm{i}$, lo que ha fructificado en la publicación de 13.500 artículos científicos, 220 libros, 863 tesis y la obtención de 95 patentes (CSIC, 2018).

Estos datos reflejan la gran importancia que tiene el organismo en el desarrollo de la investigación científica en nuestro país, siendo además la tercera mayor institución pública dedicada a la investigación de Europa. Debido a esa relevancia, 
el CSIC, como cualquier otra organización, tiene presencia en internet y las redes sociales. En la red cuenta con una página web principal (http://www.csic.es/) en la que además de presentar al organismo, sus investigaciones o las ayudas para investigadores, detalla su actualidad con los últimos descubrimientos y publicaciones que realizan sus investigadores (CSIC, s.f.c).

En cuanto a las redes sociales, cuenta con numerosos perfiles en las principales plataformas. Empezando por Twitter, por ser la red social objeto de estudio, el CSIC cuenta con hasta 129 perfiles en Twitter, distribuidos entre sus delegaciones, las bibliotecas, los centros de investigación y los grupos de investigación (CSIC, s.f.c). De entre todos, sobresale el perfil principal (@CSIC), una cuenta creada en septiembre de 2010 y que hasta la redacción del presente trabajo ha publicado 15.833 tuits, siguiendo a 1.104 perfiles y contando con un total de 920.468 seguidores. Dentro de los tuits que ha publicado, se contabilizan hasta 5.584 fotos y vídeos, lo que supone que aproximadamente un tercio de los mensajes emitidos cuenta con contenido audiovisual (Twitter, s.f.b).

El CSIC cuenta también con una gran presencia en Facebook, donde hay hasta 64 perfiles de sus distintos centros, delegaciones, grupos o bibliotecas (CSIC, s.f.d). De nuevo, sobresale un perfil principal (CSIC), que cuenta con 27.107 seguidores y donde publica su actualidad (Facebook, s.f.). Además de en Twitter y en Facebook, el CSIC tiene perfil en Instagram (@CSIC) desde el 29 de abril de 2015, donde dispone de un total de 603 publicaciones y cuenta con 7.053 seguidores (Instagram, s.f.). También YouTube cuenta con la presencia del CSIC, con un canal destinado a la divulgación (CSIC Divulga) y con otro destinado a la comunicación (CSIC Comunicación), siendo este el principal. Creado en septiembre de 2010, con 436.162 visualizaciones y 1.682 suscriptores, el organismo ha publicado un total de 196 vídeos en torno a sus distintas líneas de investigación, como la biología, las humanidades o los recursos naturales, contando cada una con una lista de reproducción propia (YouTube, s.f.).

\section{Metodología}

Vista la importancia de la imagen en la comunicación científica y la relevancia que han cobrado redes sociales como Twitter, el presente artículo cuenta con el 
El impacto del uso de la imagen en la cuenta de Twitter de CSIC | 215 ARTÍCULOS DE INVESTIGACIÓN

objetivo principal de analizar el uso que el CSIC hace de la imagen en su perfil de Twitter, contando con los siguientes objetivos secundarios:

- OS1: Estudiar la tipología de soporte y frecuencia de la imagen que el CSIC utiliza en Twitter.

- OS2: Analizar la finalidad de las imágenes utilizadas en el perfil del CSIC en Twitter.

- 0S3: Cuantificar los impactos que tienen las imágenes utilizadas en Twitter por el CSIC.

- OS4: Comparar los impactos de los tuits con imagen con la de los tuits sin imagen que publica el CSIC en Twitter.

Fruto de lo presentado en la introducción y de los objetivos perseguidos en esta investigación, se han elaborado una serie de hipótesis que presentan lo que se espera obtener de la aplicación metodológica detallada más adelante.

- H1: El CSIC hace un uso mayoritario de la imagen en el contenido que publica en Twitter.

- H2: El CSIC recurre más veces al soporte fotográfico en sus tuits, aunque también utiliza ilustraciones y vídeos.

- H3: La finalidad más habitual de las imágenes en el perfil de Twitter del CSIC es la explicativa.

- H4: Gracias a la utilización de la imagen, el CSIC consigue más impactos en Twitter.

- H5: Los tuits con imagen que publica el CSIC logran más impactos que los tuits sin imagen. 


\section{ARTÍCULOS DE INVESTIGACIÓN}

El análisis de contenido es la técnica utilizada para defender o refutar las hipótesis planteadas. Gracias a ello ha sido posible estudiar el uso que el CSIC hace de la imagen en Twitter y cuantificar el impacto de dicha utilización. Según los criterios de Piñuel (2002), se delimita el análisis de contenido utilizado de la siguiente manera:

- Según los objetivos perseguidos: se trata de un análisis de contenido verificativo y/o explicativo, puesto que establece inferencias sobre el funcionamiento y efectos de los productos comunicativos (Piñuel, 2002, p.9), en este caso de los tuits del CSIC.

- Según el objeto de estudio: el análisis realizado es horizontal o extensivo, ya que el corpus documental es muy extenso (casi 16.000 tuits del CSIC) y requiere de una selección muestral para realizar el análisis.

- Según los parámetros de medición: se trata de un análisis cualitativo y frecuencial, ya que examina elementos cualitativos, como las imágenes, dentro de cada unidad de análisis, $\mathrm{y}$, además, contabiliza las veces que aparecen ciertas categorías establecidas.

Sobre la selección muestral comentada, esta ha desembocado en la obtención de un número representativo y abarcable de publicaciones. Una selección muestral realizada mediante un muestreo polietápico según Wimmer y Dominick (2001):

- En una primera fase, en el muestreo de las fuentes del material, se recurre a la cuenta principal del CSIC en Twitter (@CSIC), desestimando la destinada a la divulgación científica (@CSICDivulga), por su menor actividad y su menor masa de seguidores. De dicha cuenta se han analizado los tuits enviados y no los retuits, por considerar que son aquellos que tienen la voluntad de comunicación propia y no la de otras cuentas retuiteadas.

- En la segunda fase, el muestreo de fechas, se han seleccionado los tuits emitidos durante el mes de septiembre de 2018, por ser fechas en las que ya se ha superado el parón veraniego y con el objetivo de recorrer toda la 
actividad de un mes completo, obteniendo un volumen de muestra representativo.

La muestra analizada incluye un total de 124 tuits. El contraste de las hipótesis presentadas se ha establecido atendiendo a la comparación de los resultados en los procedimientos señalados.

\section{Resultados}

A fin de realizar un análisis más exhaustivo y detallado de los resultados, se han presentado por separado atendiendo a las distintas categorías establecidas en la ficha de análisis utilizada. Antes de ello, es necesario comentar que, tras haber realizado el análisis de la muestra, se ha descubierto que el CSIC solo tuitea mensajes durante los días laborables, y que dichos mensajes se envían mayoritariamente en la franja horaria de 9:00 a 15:00, pudiendo deberse al hecho de que el equipo de comunicación encargado de redes sociales sea muy pequeño. Además, demuestra que el equipo de comunicación del CSIC no conoce la existencia de plataformas como Hootsuite en las que se puede programar la publicación de tuits a la hora deseada, pudiendo aumentar los impactos del perfil del CSIC a lo largo del día y no solo concentrados en el horario laboral estándar. Esto ha de ser tenido en cuenta a la hora de valorar la interacción de los usuarios, puesto que el horario mencionado es una franja en la que la mayoría de las personas se encuentra trabajando y no accede tanto a las redes sociales, siendo el impacto menor de lo que podría ser si los mensajes se emitieran en un horario más amplio.

El primer dato a destacar en el análisis realizado es el de la utilización de material audiovisual dentro del perfil en Twitter del CSIC. Durante el periodo analizado en el que se han emitido 124 tuits, el CSIC ha publicado hasta 77 tuits en los que se incluía material audiovisual de algún tipo, mientras que en 47 no se añadía ninguna imagen. Esto supone que el $62,1 \%$ de los tuits publicados incluía contenido visual, siendo un hábito mayoritario durante el periodo analizado y reflejando que el uso de la imagen está muy presente en las rutinas comunicativas del CSIC en Twitter. 


\section{ARTÍCULOS DE INVESTIGACIÓN}

Esta utilización de la imagen tiene diferencias dentro del perfil del CSIC que cabe tener en cuenta, diferencias como la forma de inclusión de las imágenes, el tipo de soporte utilizado, la función de dichas imágenes, la relación que guardan con el tuit publicado o, incluso, la propiedad del material audiovisual presentado.

En lo referente a la forma en la que se añaden las imágenes a los tuits, como se observa en la Figura 1, en el 80,52 \% de los casos el material audiovisual se añade de forma proactiva, adjuntándolo con las opciones con las que cuenta Twitter, mientras que en el 19,48 \% de los tuits con imágenes, estas aparecen fruto de la previsualización que la red social hace de hipervínculos que redirigen a noticias 0 vídeos de YouTube, no siendo posible saber si se añadió el enlace con el objetivo de que apareciera la imagen o sucedió sin previsión de ello. Este dato apoya la idea de que el CSIC dispone de una voluntad para incluir imágenes en sus tuits, puesto que el hecho de que la mayoría de las imágenes incluidas sean mediante el adjunto manual demuestra esa iniciativa proactiva para su inclusión.

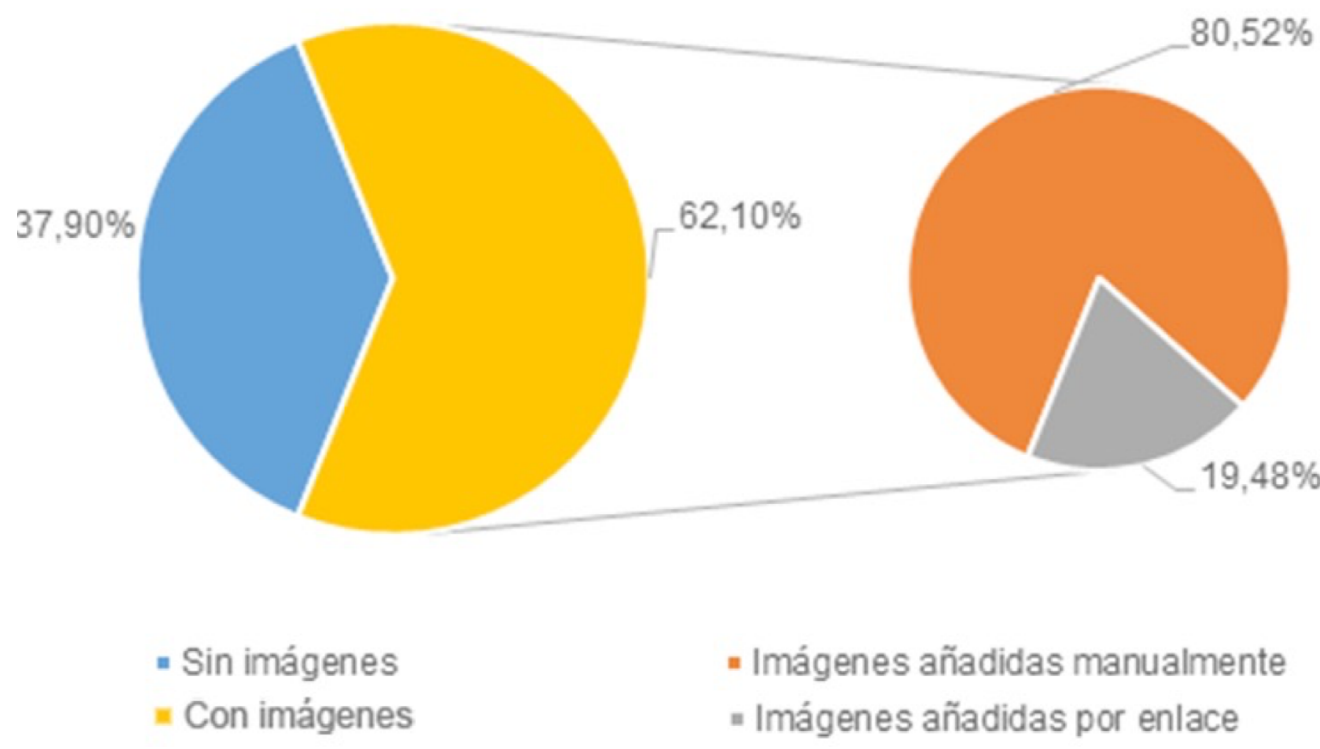

Figura 1: Porcentaje de tuits del CSIC con imagen y su tipo de inclusión. (Fuente: elaboración propia). 
Atendiendo al soporte de este contenido audiovisual, se observan hasta cinco tipos a lo largo del periodo analizado: fotografías, ilustraciones, gráficos, vídeos y GIFs. Como muestra la Figura 2, las fotografías son el soporte más recurrente, alcanzando el 67,53 \% del material audiovisual presente en el perfil del CSIC en Twitter. Las ilustraciones suponen el 12,99\% del material audiovisual utilizado durante el periodo de análisis, seguidas del uso de GIFs, que componen el 9,09\% del contenido visual utilizado. Por el contrario, la utilización del vídeo supone el $7,79 \%$ del global, mientras que los gráficos son solo utilizados en el 2,6 \% de las ocasiones. Este hecho refleja un interés por parte del CSIC de mostrar la realidad de lo que comunica y divulga sobre la ciencia, y para mostrar esa realidad el mejor soporte es el de la fotografía, que refleja lo que sucede en ese momento.

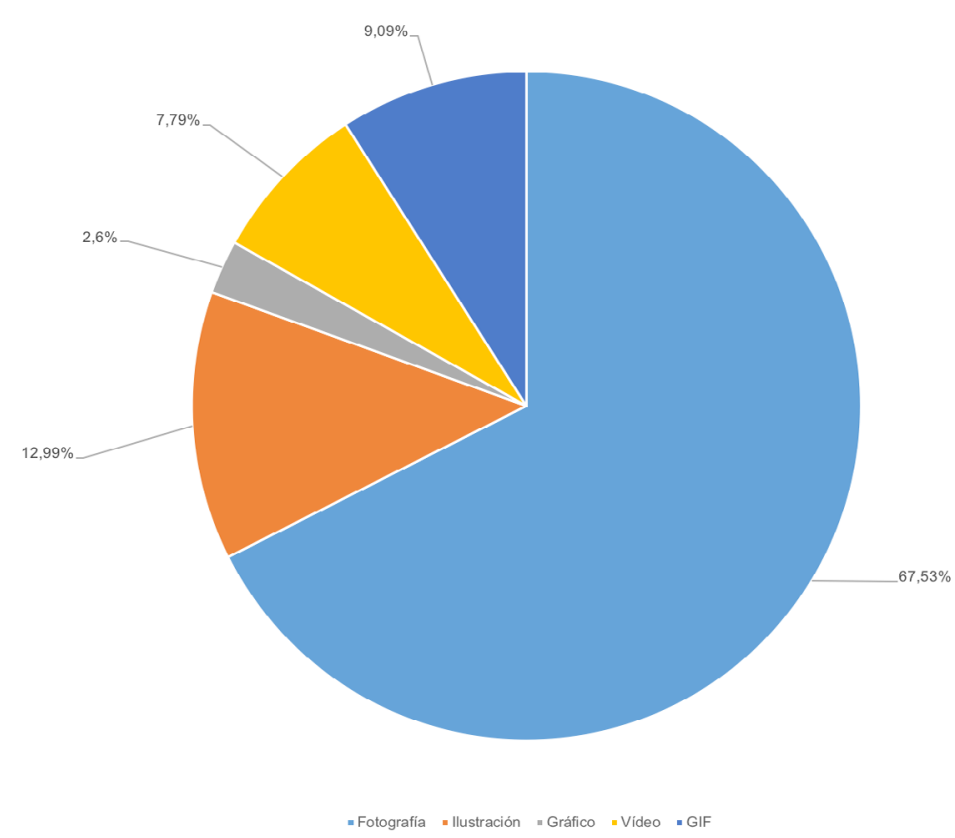

Figura 2: Porcentaje de la tipología de material audiovisual utilizado por el CSIC. (Fuente: elaboración propia).

Además de la preferencia por la imagen fotográfica, esta Figura 2 también trae a colación el mayor uso de la imagen estática. Como se puede observar, las foto- 


\section{ARTÍCULOS DE INVESTIGACIÓN}

grafías, las ilustraciones y los gráficos suponen el 83,12 \% del material visual utilizado, mientras que contenidos que incluyen imágenes en movimiento, como los GIFs o los vídeos, implican solo el 16,88 \% del material audiovisual utilizado. Esto puede deberse al mayor esfuerzo de elaboración que requiere este segundo tipo de imágenes en comparación con el primero, sobre todo en cuestiones científicas de laboratorio o de naturaleza, donde si la obtención de una fotografía ya resulta a veces complicado, la de un vídeo supone un grandísimo esfuerzo.

Menores son las diferencias entre las variables a la hora de analizar la función que tienen las imágenes incluidas en los tuits analizados. Como se puede ver en la Figura 3, la utilización de las imágenes en Twitter por parte del CSIC tiene como principal función la accesoria, es decir, como apoyo visual, con un contenido relacionado con el tuit pero sin mostrar en detalle o dar explicaciones sobre lo que explica el tuit. Esto sucede con el 46,75\% del material audiovisual utilizado, siendo la función a la que más se recurre desde el CSIC.

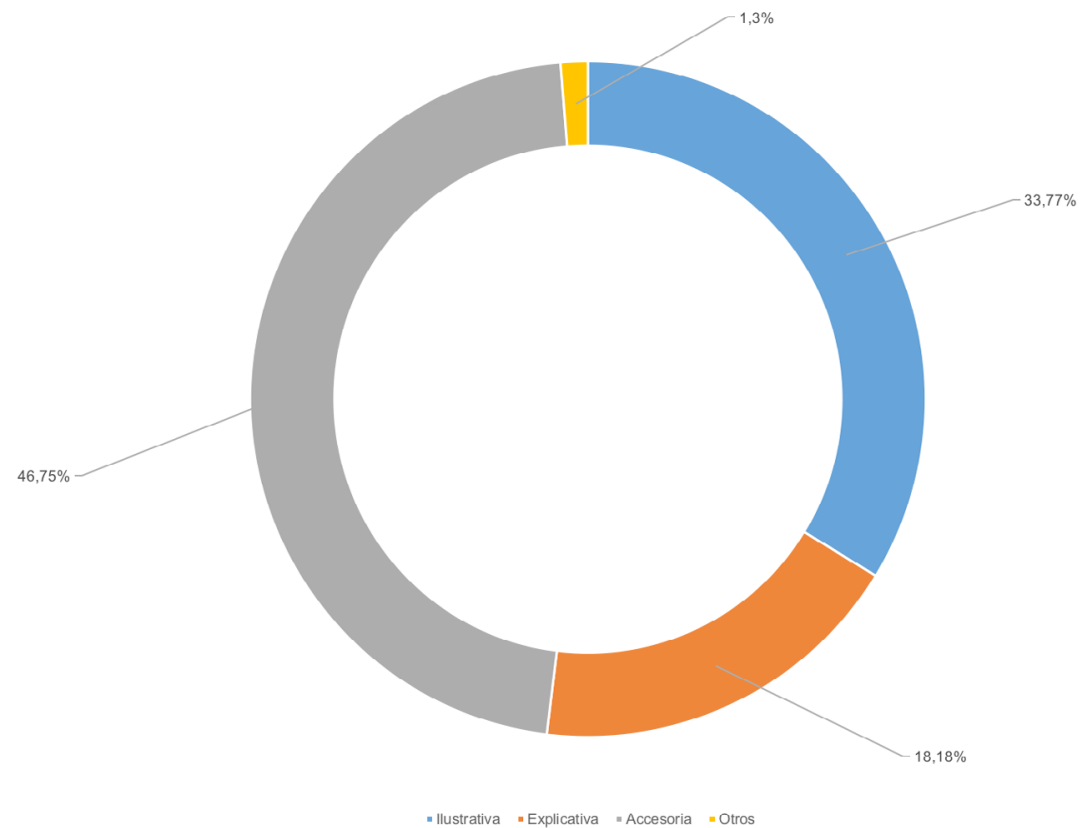

Figura 3: Porcentaje de la función de las imágenes añadidas en los tuits del CSIC. (Fuente: elaboración propia). 
Tras la accesoria, aparece como segunda función más recurrente la ilustrativa, la de mostrar visualmente la cuestión sobre la que versa el mensaje en Twitter. Esto se produce en el 33,77 \% de los casos analizados, siendo una función muy importante en la divulgación científica, puesto que pone imagen a lo que se explica en el tuit publicado. Por último, aparece la función explicativa en el 18,18 \% de los casos, donde las imágenes sirven para ampliar o justificar la información científica que se detalla en el contenido del mensaje publicado en Twitter. Aparece también un $1,3 \%$ en la categoría de "0tros", correspondiente a una imagen de un logo de un medio de comunicación que aparece en un tuit tras añadir un hiperenlace a dicho medio de comunicación y que no podría clasificarse dentro de ninguna de las otras tres categorías anteriores.

Más allá de estas categorías, la Figura 3 refleja una mayor presencia de las funciones divulgativas y educativas, como son la explicativa y la ilustrativa, que suman en conjunto un 51,95\% frente al 48,05\% de la función accesoria. Este dato pone en valor la función y la voluntad que tiene el CSIC para situarse como un ente de divulgación científica y refleja que la utilización de las imágenes es otro factor más a la hora de conseguir que la ciencia llegue, eduque y forme a los usuarios.

Continuando con la presentación de resultados, el análisis de la muestra ha reflejado una dominante relación de las imágenes con el texto del tuit, superando ampliamente a las imágenes que se relacionan con otros aspectos como los hipervínculos, las etiquetas o las menciones a otros usuarios. Como refleja la Figura 4, el 82,05\% de las imágenes utilizadas y analizadas se relaciona con el texto presente en el tuit, cifra muy superior al 11,54\% de imágenes que tienen relación con la etiqueta o hashtag del mensaje, la segunda relación mayoritaria. Menor es la relación de las imágenes con el hiperenlace utilizado, donde apenas asciende al 3,85\% de los casos, o a la mención personal utilizada, donde las imágenes que reflejan a la persona mencionada apenas suponen el 2,56 \% del total. 


\section{ARTÍCULOS DE INVESTIGACIÓN}

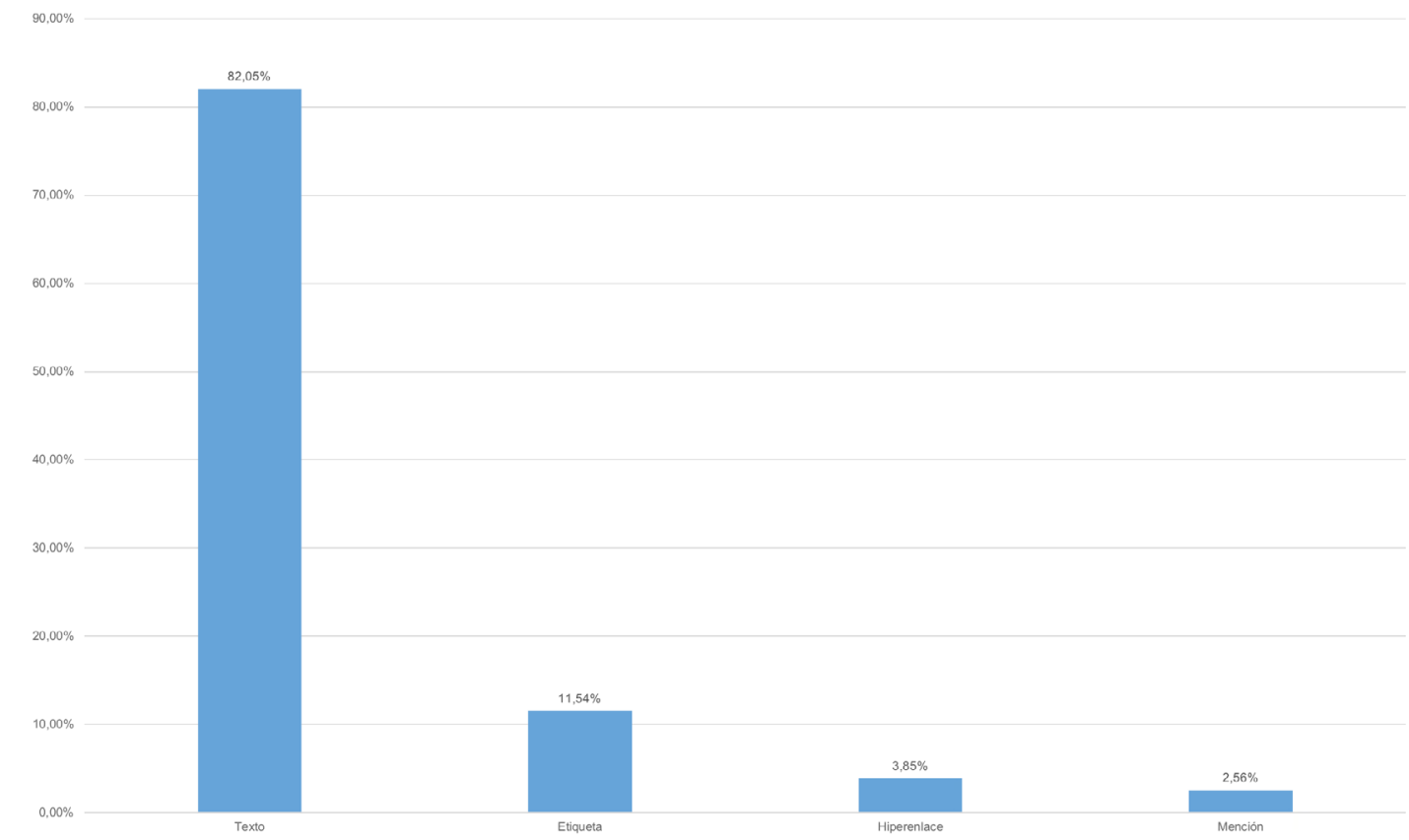

Figura 4: Porcentaje de la relación de las imágenes con el tuit del CSIC. (Fuente: elaboración propia).

Este dato está en relación con lo comentado sobre la intención del CSIC de añadir imágenes para mostrar visualmente lo que explica en el tuit, así como con la mayoritaria función divulgativa en las imágenes utilizadas, puesto que el hecho de que las imágenes estén principalmente en relación con el texto hace pensar que es porque tratan de explicar o ilustrar lo que el CSIC explica mediante la palabra, consiguiendo gracias a la imagen mejorar la comprensión del contenido por parte de los receptores.

En cuanto a la propiedad o autoría de las imágenes utilizadas durante el periodo de análisis, la Figura 5 muestra una ligera superioridad de imágenes cuya autoría es del CSIC o de alguien dependiente del mismo, suponiendo el 53,25\% de los casos, mientras que el 46,75\% restante se compone de imágenes cuya autoría es ajena al CSIC y donde se incluyen los GIFs, imágenes accesorias de bancos de imágenes o de noticias hiperenlazadas. 


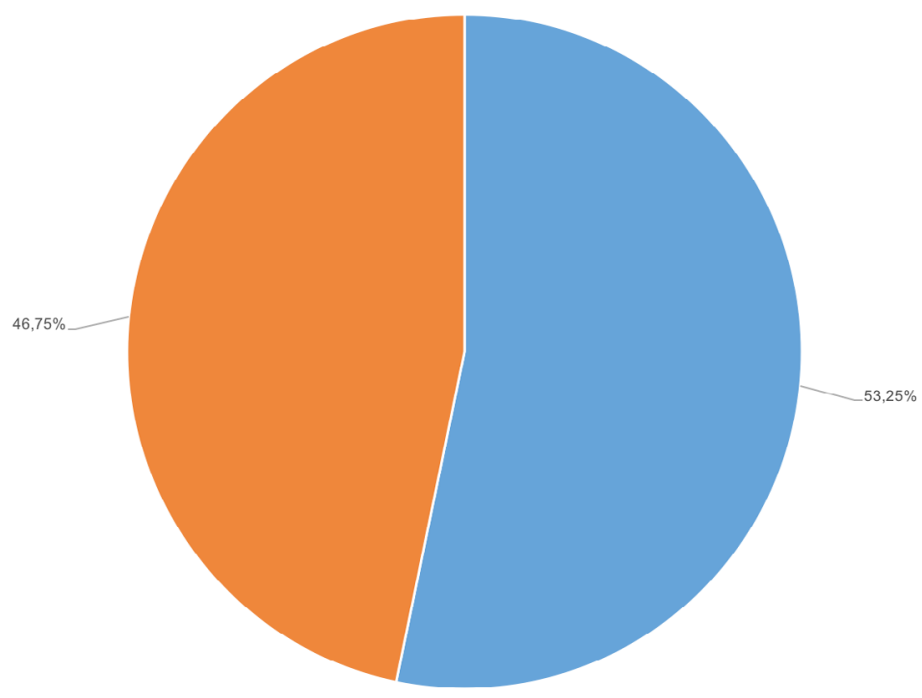

Figura 5: Porcentaje de la propiedad del material audiovisual utilizado por el CSIC en Twitter. (Fuente: elaboración propia).

De nuevo este dato pone en valor la importancia que tiene la imagen para el CSIC, puesto que además de contar con un gran número de imágenes en su perfil, la mayoría de las mismas son de elaboración propia, lo que demuestra la preocupación del ente no solo por incluirlas, sino por buscar una demostración visual de lo que explica en sus tuits. Pero no solo eso, ya que el hecho de que las imágenes de propiedad ajena tengan una cifra casi equiparable a las propias reseña que el CSIC también se implica en la utilización de contenido visual aunque no disponga del mismo, recurriendo a bancos de imágenes para presentar visualmente sus contenidos.

En cuanto al número de interacciones recibidas por parte de los usuarios se observa que aquellos tuis que incluyen imágenes de algún tipo llegan a triplicar los resultados obtenidos por los tuits que no las incluyen. De hecho, los retuits de los tuits con imagen superan en un 738,89\% a los de los tuits sin imagen, mientras que los Me Gustas lo hacen en un 623,40 \% y las respuestas en un 409,52 \%. 
ARTÍCULOS DE INVESTIGACIÓN

\begin{tabular}{|c|c|c|c|}
\hline & Retuits & Me Gusta & Respuestas \\
\hline Tuits con imagen & 3.724 & 5.860 & 86 \\
\hline Tuits sin imagen & 504 & 940 & 21 \\
\hline Total & 4.228 & 6.800 & 107 \\
\hline Diferencia & $+738,99 \%$ & $+623,40 \%$ & $+409,52 \%$ \\
\hline
\end{tabular}

Tabla 1: Número de retuits, Me Gustas y Respuestas recibidas por el CSIC. (Fuente: elaboración propia).

Traducido a ratios por tuit, los tuits con imagen reciben una media de 48,36 retuits, mientras que aquellos mensajes sin contenido visual apenas llegan a los 10,72 retuits por mensaje, siendo casi una quinta parte de lo obtenido por los primeros y demostrando la mayor interacción de los usuarios con los mensajes que incluyen imágenes, quizás debido a su mejor comprensión o al atractivo que genera la imagen en los usuarios. En cuanto al número de Me Gustas, cada uno de los tuits con contenido audiovisual publicado por el CSIC durante el periodo muestral obtuvo una media de 76,10 Me Gustas, cifra casi cuatro veces mayor a la obtenida por aquellos tuits sin imágenes, cuya media desciende hasta los 20 por tuit. Por último, las respuestas también varían en función de la utilización de imagen o no, obteniendo el CSIC una media de 1,12 respuestas en aquellos tuits que incluyen imágenes, cifra que se reduce hasta las 0,45 respuestas por tuit en aquellos mensajes que no presentan imágenes.

Durante el periodo analizado, el máximo de interacciones recibidas por un tuit con imagen asciende a 297 retuits, 445 Me Gusta y 3 respuestas, mientras que el tuit sin imagen con mayor impacto se trata de uno integrado en un hilo que preside un tuit con imagen y sus números ascienden a 26 retuits, 87 Me Gusta y 1 respuesta, como se puede ver en la Figura 6. 


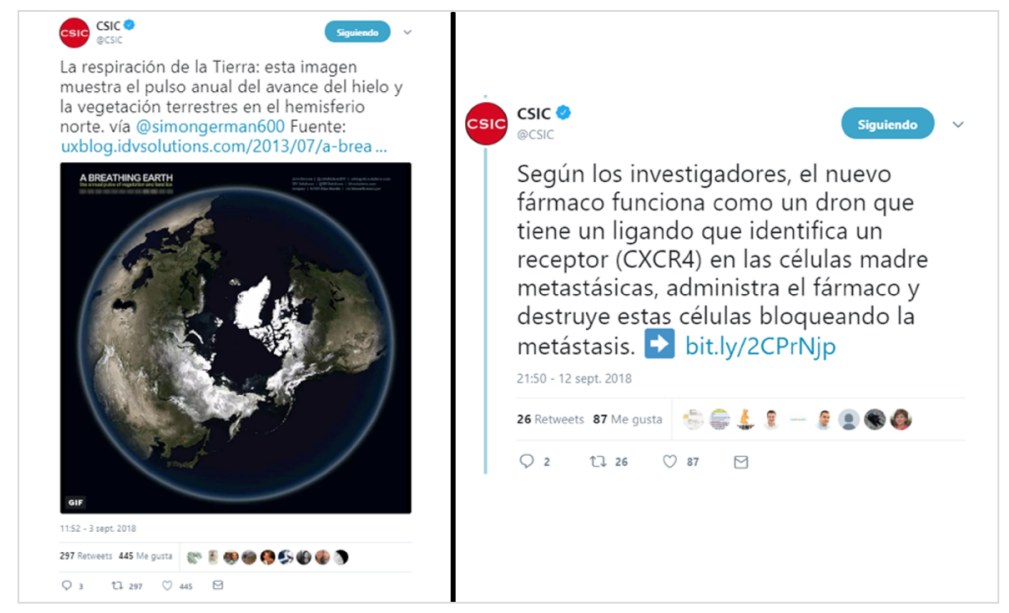

Figura 6: Tuits con imagen y sin imagen del CSIC con mayor número de interacciones durante el periodo analizado. (Fuente: Perfil en Twitter del CSIC).

Esta cantidad de interacciones no es la tónica general, puesto que durante el periodo analizado aparecen tuits con menores cifras tanto con imagen como sin ella. Sin embargo, no deja de ser reseñable que todas aquellas publicaciones que cuentan con contenido visual siempre han disfrutado de alguna interacción por parte de los usuarios, mientras que se contabilizan hasta cuatro tuits sin imágenes en los que el CSIC no recibe ni un retuit ni Me Gusta, como se ve en la Figura 7.

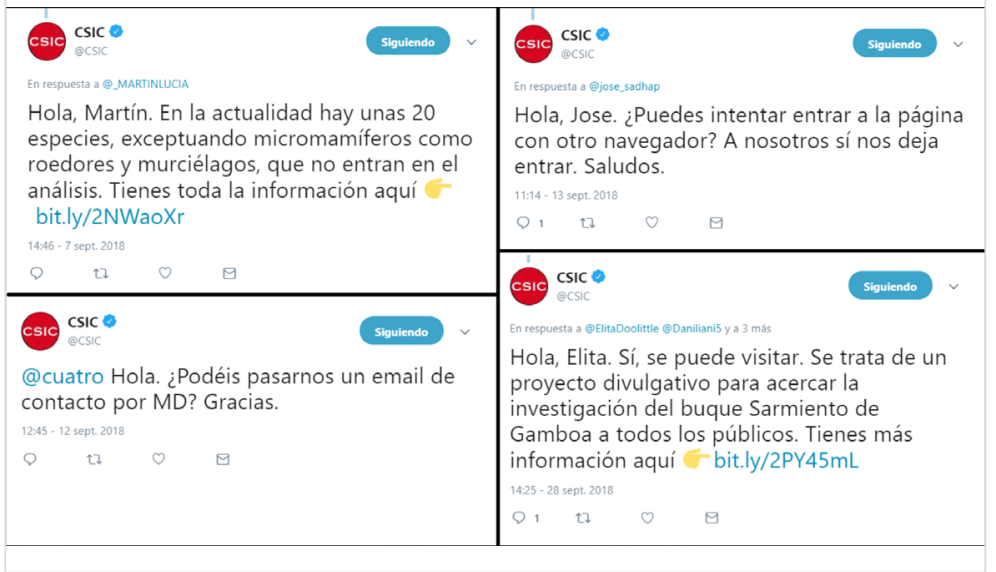

Figura 7: Ejemplos de tuits del CSIC sin interacciones. (Fuente: Perfil en Twitter del CSIC). 


\section{Discusión}

Los resultados del análisis permiten comprobar la gran importancia que tiene la utilización de la imagen dentro de las rutinas comunicativas del CSIC en Twitter. Se confirma la primera hipótesis que afirmaba que el CSIC hace un uso mayoritario de la imagen en el contenido publicado en Twitter, añadiendo material visual en el $62,1 \%$ de los tuits.

En cuanto a la tipología de soporte de las imágenes, se confirma también la segunda hipótesis de investigación que afirmaba que el CSIC recurre principalmente a la fotografía (representa un $67,57 \%$ del contenido visual analizado) y en menor medida a las ilustraciones $(12,99 \%)$ y vídeos $(9,09 \%$ de presencia de GIFs y 7,79 $\%$ de los vídeos).

La tercera hipótesis de la investigación queda refutada, puesto que la finalidad explicativa, con un 18,18 \% de presencia, no es la más habitual para las imágenes publicadas en Twitter por el CSIC, siendo la accesoria con un 46,75 \% y la ilustrativa con un 33,77\% las funciones más recurrentes.

Las cifras cuantitativas obtenidas en el análisis confirman las dos últimas hipótesis de la investigación, puesto que queda demostrado que el CSIC recibe más interactividad en Twitter en aquellos tuits que incluyen imagen, tuits que además logran más retuits, Me Gustas y respuestas que aquellos que no incluyen imagen.

Por último, como valoración final, el análisis realizado demuestra que la utilización de las imágenes supone un gran beneficio para la divulgación científica y la comunicación que realiza el CSIC en Twitter, ayudando a comunicar sus investigaciones y su actualidad de una forma más visual para sus públicos. Esta cuestión aporta más impactos y difusión al mensaje del CSIC, lo que le ha llevado a situarse como uno de los perfiles de referencia en la comunicación científica española en Twitter, como detalla el trabajo realizado por Pérez-Rodríguez, González-Pedraz y Alonso Berrocal (2018) en el que el CSIC, además, es el único organismo de investigación presente entre los mayores influencers españoles científicos en Twitter. 
Dados los resultados y las conclusiones, es turno ahora de discernir sobre la investigación realizada. Una de las limitaciones con las que cuenta la investigación es la del tamaño de la muestra. La investigación plantea el análisis de la comunicación en Twitter del CSIC durante el plazo de un mes, tiempo que según otras investigaciones resultaba suficiente, pero que en este caso se ha revelado como escaso, tal vez por la cuestión señalada de la falta de actividad en la red social durante los fines de semana y fuera del horario laboral. Para futuras investigaciones se plantea la opción de ampliar el tiempo de análisis para disponer de una muestra más consistente.

La investigación supone una interesante aproximación al campo de la comunicación científica en redes sociales desde la perspectiva de la imagen. Aporta luz a un campo de estudio de poco recorrido investigador hasta el momento y supone un acercamiento a la comprensión sobre la importancia de la imagen en la comunicación científica en redes sociales.

En cuanto a las futuras líneas de investigación se plantea interesante realizar una criba entre imágenes relacionadas directamente con el contenido científico y aquellas referidas a los actores, gestores o administradores de la ciencia. Asimismo, también resulta interesante analizar la utilización de la imagen en otros perfiles de Twitter de carácter científico, tanto españoles como internacionales y realizar una comparación entre los resultados obtenidos esta investigación y los de las otras instituciones para descubrir si los datos del CSIC son relevantes o mejorables dentro del campo científico en Twitter.

\section{Fuentes de financiación}

Este artículo ha sido apoyado por la concesión de la ayuda del Subprograma de Formación del Profesorado Universitario FPU15/07114 del Ministerio de Ciencia, Innovación y Universidades de España. 


\section{Referencias bibliográficas}

Abad, J. (2012). Imagen-palabra: texto visual o imagen textual. Congreso Iberoamericano de las Lenguas en la Educación y en la Cultura. Salamanca, España. Recuperado de https://tinyurl.com/y6o3qpb6

Berlanga, I. \& García, F. (2014). Ciberretórica: Aristóteles en las redes sociales. Madrid, España: Fragua.

Camusso, M.Á. \& Marchetti, V. (2002). Comunicación visual y contratos de lectura. La trama de la comunicación, 7, 99-114. Recuperado de https://tinyurl.com/ y5hcb8xg

Cardeñosa, T. (2018). Informe de los perfiles en redes sociales de España. The Social Media Family. Recuperado de https://tinyurl.com/yysx6dlw Castells, M. (2005). The Network Society: From Knowledge to Policy. En Castells, M. \& Cardoso, G. (Eds.) The Network Society: From Knowledge to Policy (pp.3-21). Washington DC, Estados Unidos: Johns Hopkins Center for Transatlantic Relations. Celaya, J. (2011). La empresa en la web 2.0: el impacto de las redes sociales y las nuevas formas de comunicación online en la estrategia empresarial. Barcelona, España: Gestión 2000.

CSIC (a). Antecedentes del CSIC: la JAE. Recuperado de https://tinyurl.com/y4dv27by CSIC (b). Ciencia en democracia. Recuperado de https://tinyurl.com/yxbx9v4e CSIC (c). Consejo superior de investigaciones científicas. Recuperado de https:// tinyurl.com/nqgbl

CSIC (d). Redes sociales. Recuperado de https://tinyurl.com/y4mb8j4y

CSIC (2018). Memoria anual de la actividad científico-técnica del Consejo Superior de Investigaciones Científicas. España: Agencia Estatal Consejo Superior de Investigaciones Científicas.

Díaz, A. (2015). ¿Hacemos un uso inteligente de las redes? En Criado, J. \& Rojas, F. Casos de éxito en redes sociales digitales de las administraciones públicas (pp.810). Barcelona, España: Escola d'Administració Pública de Catalunya.

Facebook. CSIC. Recuperado de https://tinyurl.com/yyd8ercq

Fernández, J. (2015). La estrategia digital integrada en la comunicación institucional. El caso de la Guardia Civil y el uso de las redes sociales. En Carrillo, V. et al. (coord.). La gestión de intangibles para la excelencia empresarial: nuevas oportunidades para la comunicación y sus profesionales (pp.412-422). Madrid, España: Campgràfic. 
Frascara, J. (2015). El poder de la imagen: reflexiones sobre comunicación visual. Buenos Aires, Argentina: Ediciones Infinito.

García, F.J. (2014). Innovación docente y redes sociales: oportunidades y retos. En Fernández, A. (coord.). Interactividad y redes sociales (pp.245-262). Madrid, España: Editorial ACCI.

García, F. \& Gértrudix, M. (2009). El Mare Nostrum Digital: mito, ideología y realidad de un imaginario socio-técnico. Revista Icono14, 12, 7-30. D0I: 10.7195/ri14.v7i1.331

Goyes, J.C. (2003). Horizontes de la comunicación visual contemporánea. Revista La Tadeo, 68.

Hernández, S. \& Subiela, B. (2012). Los mensajes de las organizaciones en las redes sociales: nuevos retos frente a las RR.PP.tradicionales. En Nicolás, M.Á. \& Grandío, M. M., Estrategias de comunicación en redes sociales (pp.63-82). Barcelona, España: Gedisa.

Instagram. Perfil del CSIC @CSIC. Recuperado de https://tinyurl.com/y58q5uqy López, L. \& Cuesta, U. (2012). Comunicación corporativa y redes sociales: cambiarlo todo para que nada cambie. Revista adComunica, 3, 23-25. D0I: 10.6035/21740992.2012.3.2

Martínez de Salinas, J. (2015). Buena práctica de la presencia del Instituto Aragonés de Empleo en los canales de la web 2.0. En Criado, I. \& Rojas, F. Casos de éxito en redes sociales digitales de las administraciones públicas (pp.57-75). Barcelona, España: Escola d'Administració Pública de Catalunya. DOI: 10.2436/10.8030.05.6 Munari, B. (2016). Diseño y comunicación visual. Barcelona, España: Gustavo Gili. Noguera, J. M., Martínez, J. \& Grandío, M.M. (2011). Redes sociales para estudiantes de comunicación: 50 ideas para comprender el escenario online. Barcelona, España: Editorial UOC.

0'Reilly, T. (2006). Web 2.0 Compact Definition: Trying Again. Radar: Insight, Analysis, and Research about emerging Technologies. Recuperado de https:// tinyurl.com/yzpzqg9

Otero, M.R., Moreira, M.A. \& Greca, I.M. (2002). El uso de imágenes en textos de Física para la enseñanza secundaria y universitaria. Investigações em Ensino de Ciências, 7(2), 127-154. Recuperado de https://tinyurl.com/y3v8cd8q

Pantoja, A. (2007). La imagen como escritura. El discurso visual para la historia. Norba. Revista de Historia, 20, 185-208. Recuperado de https://tinyurl.com/yyk9wmop 


\section{ARTÍCULOS DE INVESTIGACIÓN}

Perales, F.J. (2006). Uso (y abuso) de la imagen en la enseñanza de las ciencias. Enseñanza de las ciencias, 24(1), 13-30. Recuperado de https://tinyurl.com/ y4rgtvtt

Pérez-Rodríguez, A.V., González-Pedraz, C. \& Alonso Berrocal, J.L. (2018). Twitter como herramienta de comunicación científica en España. Principales agentes y redes de comunicación. Communication Papers - Media Literacy \& Gender Studies, 7(13), 95-111. Recuperado de https://tinyurl.com/y6kt8qby

Piñuel, J. L. (2002) Epistemología, metodología y técnicas del análisis de contenido. Estudios de Sociolingüística, 3(1), 1-42. Recuperado de https://tinyurl.com/ 049z9fz

Piscitelli, A. (2006). Nativos e inmigrantes digitales. Revista Mexicana de Investigación Educativa, 11(28), 179-185. Recuperado de https://tinyurl.com/ y3qqjr7p

Prensky, M. (2001). Digital Natives, Digital Immigrants. On the Horizon, 9(5), 1-6. Recuperado de https://tinyurl.com/y4m9hlbh

Revuelta, G. \& Corchero, C. (2017). Perfiles generacionales en el consumo de información científica. En FECYT. Percepción Social de la Ciencia y la Tecnología 2016 (pp.179-206). Madrid, España: MIC.

Statista (2018). Number of monthly active Twitter users worldwide from 1st quarter 2010 to 2nd quarter 2018 (in millions). Recuperado de https://tinyurl.com/ 04fs8mm

Twitter (a). Sobre nosotros. Recuperado de https://tinyurl.com/y3n2fp7q

Twitter (b). CSIC. Recuperado de https://tinyurl.com/y6gbkcv5

Van Dijck, J. (2008). Digital photography: communication, identity, memory. Visual Communication, 7(1), 57-76. DOI: 10.1177/1470357207084865

Wimmer, R. \& Dominick, J. (2001). Introducción a la investigación de medios masivos de comunicación. Madrid, España: Thomson.

YouTube. CSIC Departamento de Comunicación. Recuperado de https://tinyurl. $\mathrm{com} / \mathrm{y} 3 \mathrm{hr} 5 \mathrm{rqs}$

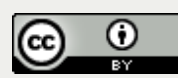

Este obra está bajo una licencia de Creative Commons Reconocimiento 4.0 Internacional. 